\title{
Differential expression of the costimulatory molecules CD86, CD28, CD152 and PD-1 correlates with the host-parasite outcome in leprosy
}

\author{
Maria de Lourdes Palermo', Maria Ângela Bianconcini Trindade ${ }^{2}$, \\ Alberto José da Silva Duarte', Camila Rodrigues Cacere', Gil Benard ${ }^{3,4} /+$ \\ ²Laboratório de Investigação Médica 56 ³aboratório de Investigação Médica 53, Divisão de Clínica Dermatológica, \\ Faculdade de Medicina ${ }^{4}$ Laboratório de Micologia Médica, Instituto de Medicina Tropical, Universidade de São Paulo, São Paulo, SP, Brasil \\ ${ }^{2}$ Instituto de Saúde, Secretaria de Estado da Saúde de São Paulo, São Paulo, SP, Brasil
}

Leprosy is a spectral disease exhibiting two polar sides, namely, lepromatous leprosy (LL) characterised by impaired T-cell responses and tuberculoid leprosy in which T-cell responses are strong. Proper T-cell activation requires signalling through costimulatory molecules expressed by antigen presenting cells and their ligands on T-cells. We studied the influence of costimulatory molecules on the immune responses of subjects along the leprosy spectrum. The expression of the costimulatory molecules was evaluated in in vitro-stimulated peripheral blood mononuclear cells of lepromatous and tuberculoid patients and healthy exposed individuals (contacts). We show that LL patients have defective monocyte CD86 expression, which likely contributes to the impairment of the antigen presentation process and to patients anergy. Accordingly, CD86 but not CD80 blockade inhibited the lymphoproliferative response to Mycobacterium leprae. Consistent with the LL anergy, there was reduced expression of the positive signalling costimulatory molecules CD28 and CD86 on the T-cells in these patients. In contrast, tuberculoid leprosy patients displayed increased expression of the negative signalling molecules CD152 and programmed death-1 (PD-1), which represents a probable means of modulating an exacerbated immune response and avoiding immunopathology. Notably, the contacts exhibited proper CD86 and CD28 expression but not exacerbated CD152 or PD-1 expression, suggesting that they tend to develop a balanced immunity without requiring immunosuppressive costimulatory signalling.

Key words: Mycobacterium leprae - costimulatory molecules - CD80 - CD86 - CD152 - PD-1

Although the prevalence of leprosy has been decreasing all over the world, hyper-endemic areas persist where the transmission of leprosy is still out of control (WHO 2010). Leprosy, caused by the bacillus Mycobacterium leprae, is a chronic, incapacitating disease that affects the peripheral nerves and skin. Leprosy manifests as a spectral disease. The lepromatous form of the disease, comprising both borderline lepromatous leprosy (BL) and lepromatous leprosy (LL), is a consequence of the impaired immune cellular response of the patient and is characterised by an antigen-specific anergy, a Th-2 pattern of immune response and a lack of control of bacilli multiplication. The tuberculoid form of the disease, comprising both borderline tuberculoid (BT) and tuberculoid tuberculoid (TT) leprosy, corresponds to the more benign form of the disease and is characterised by a strong granulomatous response and the control of bacilli multiplication (Yamamura et al. 1991, Sinsimer et al. 2010).

Thus, a protective immune response in leprosy is considered to rely on the cellular arm of the immune system, specifically on the generation of helper T-cells

Financial support: FAPESP, CNPq, CAPES, Fundação Paulista contra a Hanseníase

+ Corresponding authors: mahong@usp.br

Received 3 March 2012

Accepted 27 July 2012 that can activate cells from the monocytic lineage (macrophages, dendritic cells and Schawnn cells, among others) to destroy the bacilli that they harbour, along with effector T-cells, rendering them capable of killing these infected cells. Therefore, T-cell activation is a crucial step in leprosy immunity (Murray et al. 2007). The activation of T-cells by cognate antigens to proliferate and release cytokines requires a two-step signalling process. The first signal is produced by the interaction between the T-cell receptor and the antigen-major histocompatibility complex provided by the antigen-presenting cell and the second signal is mediated through the interaction of costimulatory molecules present on the surfaces of the antigen presenting cells (APCs) with their ligands on the T-cells (Mueller et al. 1989). The latter is crucial for driving the balance between the induction of tolerance or anergy and productive T-cell effector and helper immune responses. CD80 and CD86 are molecules expressed by APCs that play a major role in the outcome of T-cell activation. Although structurally and functionally similar (Bhatia et al. 2006), they exhibit different immunological properties leading to distinct T-cell functional outcomes. CD86 has a higher relative affinity for CD28, while $\mathrm{CD} 80$ has higher affinity for CD152 (Collins et al. 2002). CD28 is involved in productive T-cell activation, signalling for cellular proliferation, interleukin (IL)-2 secretion and cell survival through enhanced Bcl-2 expression (Bour-Jordan et al. 2011), while CD152 halts T-cell activation, favours apoptosis and induces either anergy or tolerance (Fife \& Bluestone 2008). Moreover, while 
CD86 and CD28 are constitutively expressed by APC and T-cells, respectively, CD80 and CD152 are expressed only following 24-48 $\mathrm{h}$ of activation of the APC and Tcell (Lenschow et al. 1996, Bour-Jordan et al. 2011). A model of T-cell costimulation has thus been proposed in which the distinct structures and binding properties of CD86 and CD80 significantly enhance the activating and inhibitory functions of $\mathrm{CD} 28$ and CD152, respectively (Collins et al. 2002). This seems to be relevant to the regulation of the immune responses in several clinical conditions. For example, the increased expression of CD86 by monocytes was shown to play a key role in the exacerbated inflammatory response of multiple sclerosis (Filion et al. 2003); conversely, the defective expression of CD86 on monocytes was shown to be crucial in uraemia-associated immunodeficiency (Girndt et al. 2001).

However, other costimulatory molecules have been described that influence the subsequent adaptive immune responses, such as programmed death-1 (PD-1) and inducible costimulatory protein (ICOS) (Greenwald et al. 2005). These molecules have been shown to play major roles in triggering autoimmunity or peripheral tolerance and directing the protective immune response to pathogens or facilitating the persistence of the parasite leading to chronic immune activation (Zhu et al. 2011, Bour-Jordan et al. 2011).

This study aimed to verify the influence of costimulatory molecules on the immune response of subjects along the leprosy spectrum. The expression levels of the costimulatory molecules CD80, CD86, CD28, CD152, PD-1 and ICOS were evaluated in in vitro-stimulated peripheral blood mononuclear cells (PBMCs) from both lepromatous and tuberculoid patients and healthy exposed individuals.

\section{PATIENTS, MATERIALS AND METHODS}

Patients and healthy contacts - A total of 28 consecutive, newly diagnosed leprosy patients admitted to our service were analysed. All patients were studied before the start of the specific therapy; they were all human immunodeficiency virus-negative and had no other infectious comorbidities. Some of the patients had participated in a previous study (Palermo et al. 2012). Fourteen had tuberculoid leprosy (age range $43 \pm 5$ years, 4 female and 10 male subjects), 11 of whom presented with the BT and three of whom presented TT. The other 14 patients had LL (age range $38 \pm 4$ years, 6 female and 8 male subjects); of these patients, 10 had BL and four presented polar LL. A control group composed of 10 healthy $M$. leprae-exposed individuals (contacts, age range $32 \pm 4$ years) was selected from among persons living in close contact with the LL patients. Exposure was defined by a positive response in the lymphoproliferation assay with M. leprae antigen, as described below (Table). The study was approved by the Ethical Committee of the Clinics Hospital, University of São Paulo Medical School (protocol 0955/08). Informed consent was obtained from all participants.

PBMC isolation and cultures - PBMCs were cultured as previously described (Cacere et al. 2008). Briefly, PBMCs were isolated from heparinised peripheral blood by a density gradient and then resuspended in RPMI medium supplemented with gentamicin $(40 \mu \mathrm{g} / \mathrm{mL})$ and $10 \%$ human AB serum (Sigma-Aldrich, St. Louis, MO, USA). PBMCs $\left(2.5 \times 10^{5} /\right.$ well $)$ were cultivated at $37^{\circ} \mathrm{C}$ and $5 \% \mathrm{CO}_{2}$ in the presence of medium only, a cell wall preparation from M. leprae (MLCwA) $(10 \mu \mathrm{g} / \mathrm{mL})$ or, as a positive control, phytohaemagglutinin (PHA) $(5 \mu \mathrm{g} /$ mL) (Sigma, Saint Louis, MO, USA). For the lymphoproliferation assays, cells were incubated for three days (PHA) or six days (MLCwA) and then pulsed for an additional $18 \mathrm{~h}$ with $1.0 \mu \mathrm{Ci} /$ well $[3 \mathrm{H}]$-thymidine (Radiochemical Centre, Amersham, UK) before harvesting. Cell-bound radioactivity was measured using a $\beta$-counter (Perkin-Elmer, Boston, MA, USA). In some experiments, the following blocking monoclonal antibodies were added to the cultures, at $10 \mu \mathrm{g} / \mathrm{mL}$, from the start of the culture (day 0), as described elsewhere (Cacere et al. 2008): anti-CD152 (IgG2a, clone BI3) (BD Pharmingen, San Diego, CA, USA), anti-CD80 (IgG1,6 clone 2D10.4) (eBioscience, San Diego, CA, USA) and anti-CD86 (IgG2b, clone IT2.2) (eBioscience).

The expression of costimulatory molecules by monocytes and T-cells - For T-cell staining, PBMCs, which were isolated as described above from both the contacts and the leprosy patients, were cultured in 24-well plates for four days and the cells were then carefully collected. Day 4 was considered to be optimal for the expression of $\mathrm{CD} 152$ and the $\mathrm{B} 7$ family of molecules on T-cells according to preliminary time-course experiments and previous reports (Cacere et al. 2008). The cells were washed twice with cold phosphate buffered saline (PBS) and then re-suspended at $1 \times 10^{6}$ cells $/ \mathrm{mL}$ in PBS/bovine serum albumin (BSA) 1\% buffer. Aliquots containing $2.5 \times 10^{5}$ cells were distributed to cytometer tubes and the Fc receptors were blocked by incubation for $20 \mathrm{~min}$ with human immunoglobulin $(50 \mathrm{mg} / \mathrm{mL})$ (Baxter Biosciences, Vienna, Austria). After washing with PBS-BSA $1 \%, 10 \mu \mathrm{L}$ of the following antibodies was added: anti-CD3 (tri-colour, Caltag) and anti-CD28 (PE, Caltag), anti-CD152 (Cy-chrome, Pharmingen), anti-PD-1 (FITC, eBioscience), anti-ICOS (PE, eBioscience), anti-CD80 (FITC, Caltag) or anti-CD86 (PE, Caltag). To analyse the expression of CD86 and CD80 on peripheral blood monocytes, $\mathrm{CD} 14^{+}$cells were isolated from the entire PBMC population by positive selection with anti-CD14-conjugated beads (EasySep, StemCell Technologies). The purity of the population was always $\geq 98 \%$. The purified $\mathrm{CD}_{14}{ }^{+}$population was allowed to rest in 24-well plates for $48 \mathrm{~h}$ at $37^{\circ} \mathrm{C}$ and $5 \% \mathrm{CO}_{2}$, a step that was necessary for the cells to return to a resting state after the column passage. After the $24 \mathrm{~h}$ resting period, MLCwA or Candida Metabolic Antigen (SanofiPasteur, Paris, France) $(5 \mu \mathrm{g} / \mathrm{mL})$, a control non-related antigen, was added and the incubation was continued for $4 \mathrm{~h}$. Monocytes were carefully collected from the wells through several washes with cold RPMI using a $1 \mathrm{~mL}$ pipette and the cells were washed again with PBS/BSA $1 \%$, resuspended in PBS/BSA $1 \%$ buffer at $10^{6}$ cells $/ \mathrm{mL}$ and stained with $10 \mu \mathrm{L}$ of the following antibodies: antiCD14 (tri-colour, Caltag, Burlingame, CA, USA) plus anti-CD80 (FITC, Caltag) or anti-CD86 (PE, Caltag). For 
TABLE

Lymphocyte proliferative responses

\begin{tabular}{lccc}
\hline Subjects & $\begin{array}{c}\text { Medium } \\
(\mathrm{cpm})\end{array}$ & $\begin{array}{c}\text { MLCwA } \\
(\mathrm{cpm})\end{array}$ & $\begin{array}{c}\text { Phytohaemagglutinin } \\
(\mathrm{cpm})\end{array}$ \\
\hline $\begin{array}{l}\text { Contacts } \\
(\mathrm{n}=9)\end{array}$ & $521 \pm 66$ & $6.216 \pm 621$ & $27.351 \pm 7.457$ \\
$\begin{array}{l}\text { Tuberculoid leprosy } \\
(\mathrm{n}=11)\end{array}$ & $744 \pm 266$ & $6.734 \pm 1771$ & $28.813 \pm 9.331$ \\
$\begin{array}{l}\text { Lepromatous leprosy } \\
(\mathrm{n}=13)\end{array}$ & $509 \pm 138$ & $1.120 \pm 149^{a}$ & $34.379 \pm 7.606$ \\
\hline
\end{tabular}

$a: \mathrm{p}<0.01$ vs. contacts and tuberculoid leprosy (one-way analysis of variance with Newmans-Keuls post-test); cpm: counts per minute; MLCwA: Mycobacterium leprae antigen.

both T-cell and monocyte staining, the tubes containing the labelled cells were gently vortexed and incubated in the dark for $30 \mathrm{~min}$ at room temperature, resuspended in $500 \mu \mathrm{L}$ of PBS/BSA $1 \%$ buffer, washed in PBS to remove unbound antibody and finally suspended in PBSazide. In each experiment, one tube remained without $\mathrm{mAb}$ addition as an autofluorescence control. In addition, each protocol was set up with colour compensation controls. Cells were immediately acquired and analysed on a Coulter flow cytometer using the software System II (Coulter Epics XL-MCL, Hialeah, FL, USA). The results were expressed as percentages of costimulatory molecule-expressing cells and mean fluorescence intensities (MFIs) per at least $10,000 \mathrm{CD}^{+}$or $\mathrm{CD}^{+} 4^{+}$gated cells.

Statistical analysis - The comparison of data from among the three groups was performed using one-way analysis of variance and the Newman-Keuls multiple comparison test. The differences were considered significant when $\mathrm{p}<0.05$. GraphPad Prism 5.0 software was used (Graph Pad Software Inc San Diego, CA).

\section{RESULTS}

Proliferative responses - The Table shows that the PBMCs of patients with the lepromatous form of leprosy were anergic to MLCwA, while positive responses were observed for the tuberculoid patients and contacts. The responses to PHA were not significantly different among the three groups.

CD86 and CD80 expression by $\mathrm{CD}_{14^{+}}$cells - Significantly fewer monocytes (CD14 ${ }^{+}$cells) from lepromatous patients $(\sim 50 \%)$ expressed the costimulatory molecule CD86 compared with tuberculoid patients and contacts $(\sim 80 \%)$ after $4 \mathrm{~h}$ of culture in the presence of medium only or MLCwA (Fig. 1A). There were no significant differences in CD86 expression when the monocytes were challenged with a control antigen from Candida spp. The analysis of the CD86 MFI data revealed a similar trend; monocytes from lepromatous patients expressed the molecule at lower densities in the presence of medium only or MLCwA (Fig. 1B). In contrast, CD80 was poorly expressed by monocytes $(<10 \%)$ that were either unchallenged or challenged with the antigens, with no significant differences among the three groups (data not shown).
The expression of costimulatory molecules by $\mathrm{CD}^{+}$ cells - CD28 was similarly expressed by high percentages of $\mathrm{CD}^{+}$cells from all three groups of patients (Fig. 2C); however, the MFI differed among the groups (Fig. 2D). $\mathrm{CD}^{+}$cells from unstimulated and MLCwA-stimulated cultures of PBMCs from both lepromatous patients
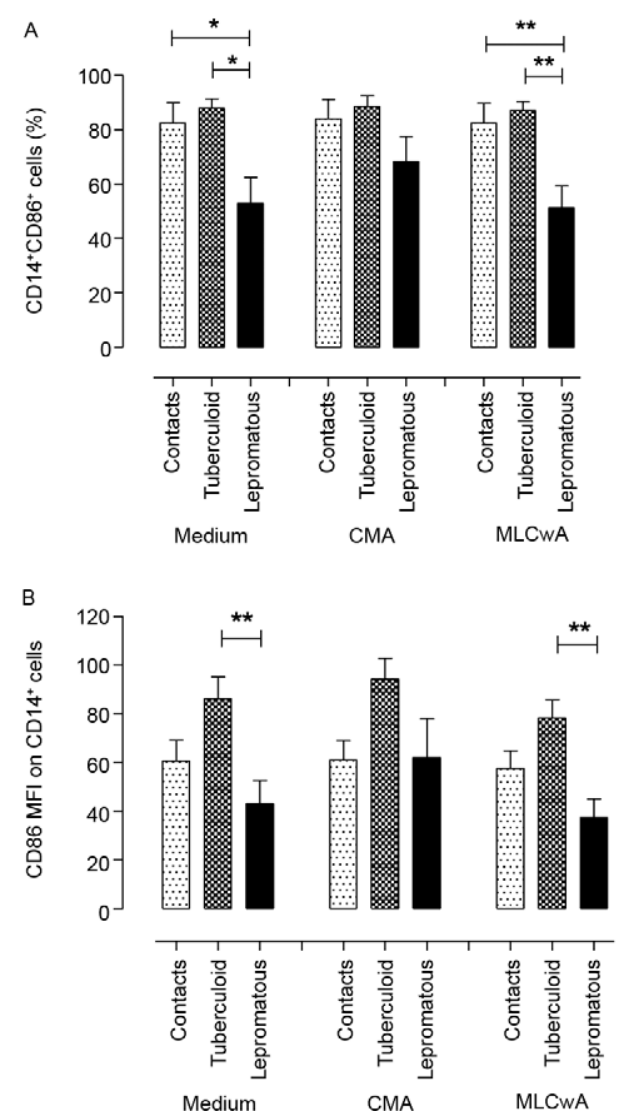

Fig. 1: expression of CD86 on monocytes (CD14 ${ }^{+}$cells) from tuberculoid $(n=7)$ and lepromatous $(n=10-11)$ leprosy patients and healthy exposed contacts $(\mathrm{n}=6)$ challenged with Candida Metabolic Antigen (CMA) or a Mycobacterium leprae antigen (MLCwA) or unchallenged (medium). Results are presented as mean \pm standard error of the means of the percentage of expressing cells (A) and mean fluorescence intensity (MFI) of the molecule (B). *: $\mathrm{p}<0.05$; **: $\mathrm{p}<0.01$. 

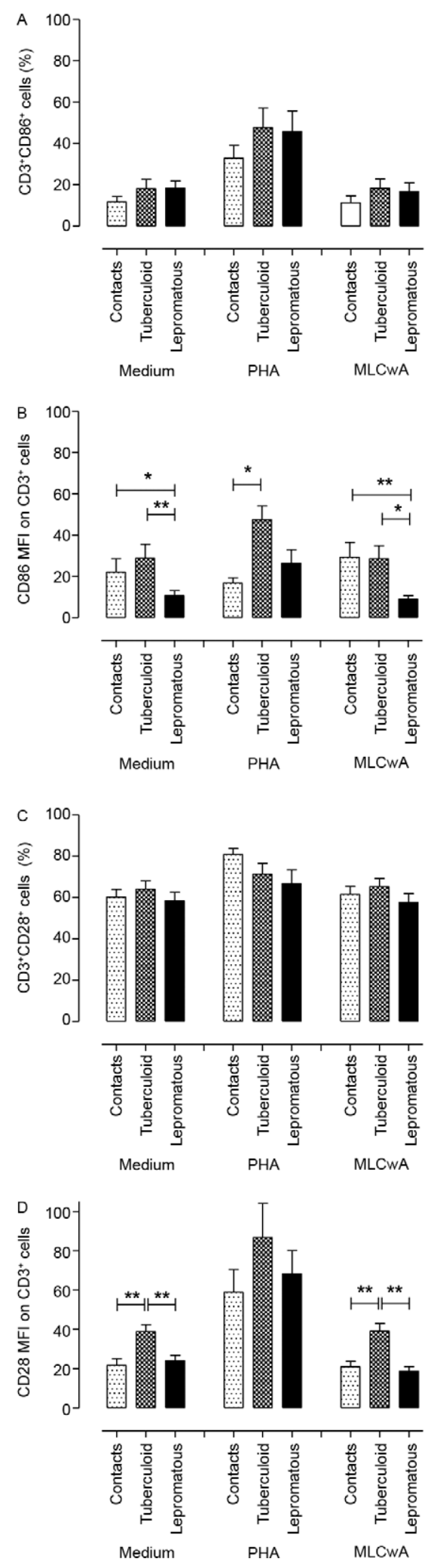

Fig. 2: expression of CD86 and CD28 on T-lymphocytes $\left(\mathrm{CD}^{+}\right.$cells) from tuberculoid $(n=10)$ and lepromatous $(n=12-14)$ leprosy patients and healthy exposed contacts $(\mathrm{n}=10)$ stimulated with phytohemaglutinnin (PHA) or a Mycobacterium leprae antigen (MLCwA) or unstimulated (medium). Results are presented as mean \pm standard error of the means of the percentage of expressing cells $(\mathrm{A}, \mathrm{C})$ and mean fluorescence intensity (MFI) of the molecule (B, D). *: $p<0.05 ; * *$ : $<<0.01$. and contacts expressed CD28 at lower intensities than those from tuberculoid patients. The CD28 MFI was comparable in $\mathrm{CD}^{+}$cells stimulated with PHA, which was used as a positive control.

As observed above for $\mathrm{CD}^{+} 4^{+}$cells, CD80 expression in unstimulated and MLCwA-stimulated $\mathrm{CD}^{+}$cells was poor $(<10 \%)$ in all three groups (data not shown). CD86 was expressed by higher numbers of $\mathrm{CD}^{+}$cells, but with no significant differences among the three groups (Fig. 2A). However, the MFI of CD86 in lepromatous patients' $\mathrm{CD}^{+}$cells was significantly reduced compared with the MFIs from tuberculoid patients and contacts in all three experimental conditions (Fig. 2B).

The expression of the negative signalling molecules CD152 and PD-1 also differed among groups (Fig. 3). Higher proportions of unstimulated and PHA and MLCwA-stimulated $\mathrm{CD}^{+}$cells from tuberculoid patients expressed CD152 with a higher MFI than the same cells from lepromatous patients and contacts (Fig. 3A, B). With regard to $\mathrm{PD}-1$, significantly higher proportions of $\mathrm{CD}^{+}$cells from both lepromatous and tuberculoid patients expressed this molecule compared with contacts either when cultured in medium only or in the presence of MLCwA (Fig. 3C). With PHA, the patients' $\mathrm{CD}^{+}$cells also expressed higher levels than the cells from contacts, although the differences did not reach statistical significance. PD-1 MFI did not differ among groups (Fig. 3D).

ICOS expression was low in $\mathrm{CD}^{+}$cells and was not different among groups in any of the experimental conditions studied (data not shown).

Blocking experiments - We tested the effect of antiCD152, anti-CD86 and anti-CD80 blocking antibodies in PBMC cultures from six donors, three tuberculoid patients and three contacts who had positive proliferative responses to MLCwA. As shown in Fig. 4, CD86 blockade reduced the proliferative response to MLCwA to less than $50 \%$ of the control cultures while CD80 blockade had no effect; CD152 blockade slightly but significantly increased the response.

\section{DISCUSSION}

Our data demonstrate that CD86, but not CD80, seems to play a critical role in the presentation of leprosy antigens by monocytes. The blockade of CD86 signalling, but not the blockade of CD80 signalling, with a neutralising monoclonal antibody resulted in significant inhibition of the proliferative response to $M$. leprae antigens. Accordingly, CD86, but not CD80, was differentially expressed among contacts and patients; the former was highly expressed by monocytes from both healthy individuals exposed to $M$. leprae (contacts) and patients at the tuberculoid pole of leprosy, while the latter was poorly expressed by both patients and contacts. In contrast, monocytes from patients at the LL pole exhibited a striking deficiency in the expression of CD86. This deficiency may help to explain the well-described differences in the T-cell responses between lepromatous and tuberculoid patients (Yamamura et al. 1991). In fact, unlike the tuberculoid patients, our lepromatous patients were unable to mount strong cellular immune responses against $M$. leprae antigens, as demonstrated in vivo by the poor granulomatous 

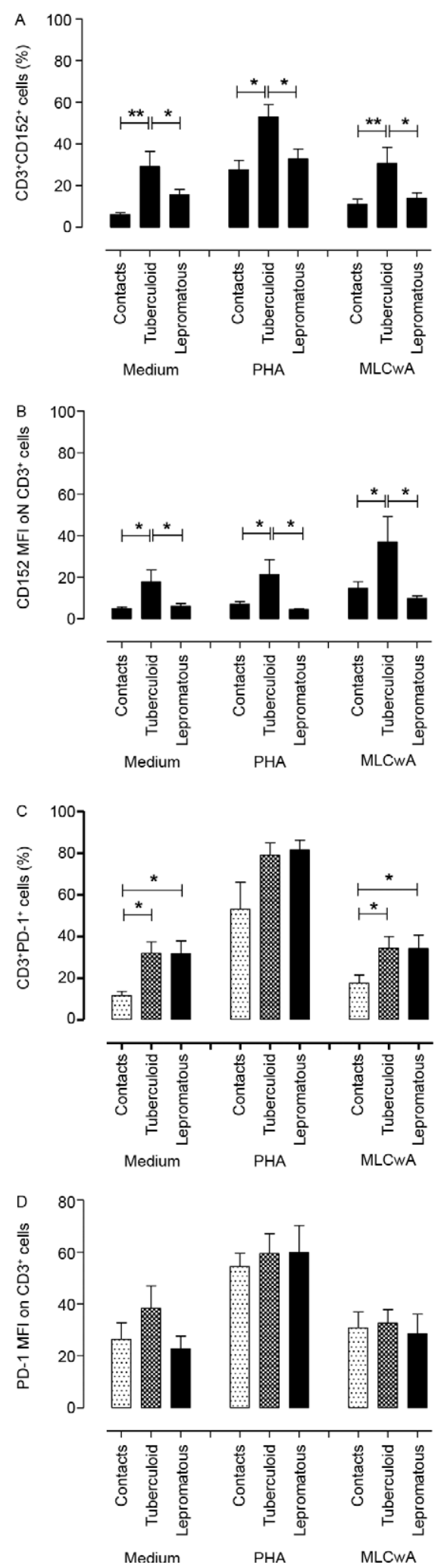

Fig. 3: expression of CD152 and programmed death-1 (PD-1) on Tlymphocytes $\left(\mathrm{CD}^{+}\right.$cells) from tuberculoid $(\mathrm{n}=9-14)$ and lepromatous $(\mathrm{n}=10-11)$ leprosy patients and healthy exposed contacts $(\mathrm{n}=$ 8) stimulated with phytohemaglutinnin (PHA) or a Mycobacterium leprae antigen (MLCwA) or unstimulated (medium). Results are presented as mean \pm standard error of the means of the percentage of expressing cells $(\mathrm{A}, \mathrm{C})$ and mean fluorescence intensity (MFI) of the molecule (B, D). *: $\mathrm{p}<0.05 ; * * \mathrm{p}<0.01$. inflammatory response and high bacillary load reported in a previous study (Palermo et al. 2012) and as observed in vitro in this study by the reduced antigen-specific proliferative responses. These findings may be explained by the reduced expression of CD86 during the early stage of recognition and presentation of $M$. leprae-derived antigens in lepromatous lesions, which interferes with the formation of the immune synapse that is required to efficiently activate the T-cells and generate effector T-cells (Lanzavecchia \& Sallusto 2000).

Previous data on CD80 and CD86 in leprosy are scarce and controversial, suggesting either a role for CD80 in the anergy of lepromatous patients or enhanced CD80 expression as a predictor of reaction states (Agrewala et al. 1998, Schlienger et al. 1998, Santos et al. 2007). Differences in the methods and the types of cells analysed and in the nature of the antigen used may account for the different results.

Several mechanisms may be put forward to explain the deficient CD86 expression by LL patients. T-regs have been shown to down-modulate the expression of CD80 and CD86 on APCs (Cederbom et al. 2000), likely through direct cell-to-cell interactions. We have previously demonstrated that these patients have increased numbers of T-regs, both in situ and in vitro (Palermo et al. 2012). IL10 has been shown to down-modulate CD86 expression on monocytes (Creery et al. 1996). In LL, the monocytes are exposed to highly IL-10-enriched microenvironments because in this form of leprosy, IL-10 expression is significantly enhanced in both in situ and in vitro-stimulated PBMCs; in contrast, in tuberculoid leprosy, the IL-10 levels are low (Moubasher et al. 1998, Palermo et al. 2012). Alternatively, the process of monocyte invasion by $M$. leprae by itself could down-modulate CD86 expression on the host cell, as has been demonstrated with Mycobacterium tuberculosis infection (Castaño et al. 2011).

Differential costimulatory molecule expression by T-cells was also verified among our lepromatous and tuberculoid patients and contacts. Molecules that either signal for (CD86 and CD28) or reduce (CD152 and PD-1) T-cell activation were evaluated. Probably as a con-

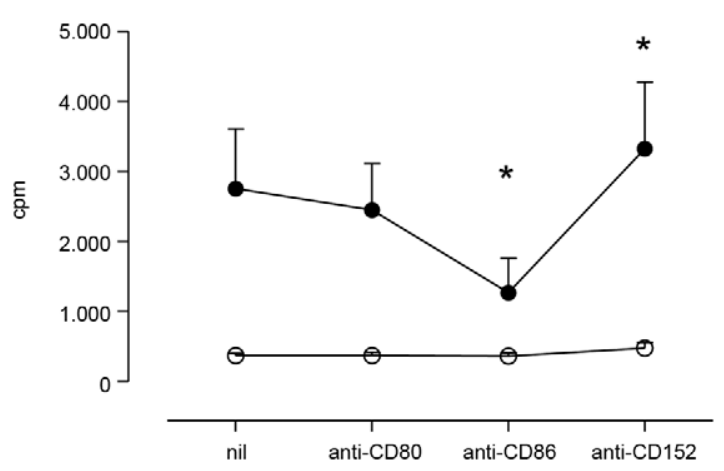

Fig. 4: effect of anti-CD80, anti-CD86 and anti-CD152 blocking monoclonal antibodies on the lymphocyte proliferative response to Mycobacterium leprae antigen (MLCwA) of six subjects responders ( 3 contacts and 3 tuberculoid patients) to MLCwA $(\bullet)$. No effect was seen in unstimulated cells (०). *: $\mathrm{p}<0.05$ vs. nil. 
sequence of defective APC function, T-cells from lepromatous patients were driven to an anergic state and exhibited reduced expression of both CD86 and CD28, especially when compared with tuberculoid patients. The latter exhibited the highest levels of expression, especially regarding CD28 expression, which was even significantly higher than even that of the contacts. This would indicate an on-going exacerbated T-cell response. However, T-cells from these patients also exhibited enhanced CD152 expression, possibly preventing an uncontrolled immune reaction. The net result would be an effective immune response capable of limiting bacillary multiplication and the dissemination of lesions without causing immunopathology. The expression of CD152 by the T-cells from contacts was significantly lower than that from tuberculoid patients, which suggests that distinct immune regulatory mechanisms take place in tuberculoid patients' and contacts' $M$. leprae-specific responses. Consistent with the fact that CD152 expression is cell-activation dependent, when resting-state molecules found in intracellular reservoirs are rapidly mobilised to the cell surface (Schneider et al. 2006), Tcells from lepromatous patients exhibited low levels of expression of this molecule. Moreover, corroborating with its inhibitory function in leprosy, the blockade of CD152 resulted in a slight but significant enhancement of the M. leprae-specific proliferative responses.

Interestingly, the pattern of expression of the inhibitory molecule PD-1 differed from that of CD152. In fact, it has been suggested that PD-1 and CD152 play complementary and non-overlapping roles in peripheral T-cell hypo-responsiveness (Fife \& Bluestone 2008). CD152 may predominantly control the T-cell response at the induction phase, while PD-1 may be responsible for the maintenance of the tolerant or anergic state. PD-1 intrinsically inhibits the function of effector T-cells (Fife et al. 2006) and it may also act by affecting the stability of their ligation with DCs (Fife et al. 2009). A significantly higher number of T-cells expressed PD-1 in tuberculoid and lepromatous patients than in contacts, thus serving as a marker of disease. In fact, PD-1 is highly expressed in situations of high and constant antigen exposure, such as chronic viral infections or malignancy (Barber et al. 2006, Zhu et al. 2011). Chronic exposure to mycobacterial antigens is indeed a feature of leprosy patients due to the protracted evolution of the disease.

Finally, the T-cell expression levels of CD80 and ICOS were also examined and indicated low levels of expression (data not shown), likely suggesting that they play minor roles in the regulation of the immune response in leprosy.

Based on our findings, a model can be built that proposes that, in LL, the defective APC function due to reduced CD86 expression by these cells results in an abnormal T-cell activation characterised by reduced antigen-specific proliferative responses and the deficient expression of CD28 and CD86 on T-cells. CD152 is not required for the induction of this anergic state. However, the chronic exposure to $M$. leprae antigens enhances PD-1 expression, which reinforces the state of tolerance against the bacillus. Consequently, patients develop a dis- seminated multi-bacillary disease. In tuberculoid leprosy, proficient APC function exists, positive proliferative responses are detected and high expression levels of positive signalling molecules on T-cells (CD28 and CD86) are detected. However, these positive signalling molecules need to be counter-regulated by the enhanced expression of inhibitory molecules (CD152 and PD-1), thus allowing a balanced effective immune response to be reached, i.e., control of the parasite burden without causing immune pathology. In contacts, there is no deficiency in the antigen-presenting process and a balanced immune response "naturally" develops because enhanced expression of negative signalling molecules is not required. A better understanding of the immune regulation of the host immune response in leprosy may allow for immune interventions that would impact the prognosis of this still poorly controlled infectious disease.

\section{REFERENCES}

Agrewala JN, Kumar B, Vohra H 1998. Potential role of B7-1 and CD28 molecules in immunosuppression in leprosy. Clin Exp Immunol 111: 56-63.

Barber DL, Wherry EJ, Masopust D, Zhu B, Allison JP, Sharpe AH, Freeman GJ, Ahmed R 2006. Restoring function in exhausted CD8 T cells during chronic viral infection. Nature 439: 682-687.

Bhatia S, Edidin M, Almo SC, Nathenson SG 2006. B7-1 and B7-2: similar costimulatory ligands with different biochemical, oligomeric and signaling properties. Immunol Lett 104: 70-75.

Bour-Jordan H, Esensten JH, Martinez-Llordella M, Penaranda C, Stumpf M, Bluestone JA 2011. Intrinsic and extrinsic control of peripheral T-cell tolerance by costimulatory molecules of the CD28/B7 family. Immunol Rev 241: 180-205.

Cacere CR, Mendes-Giannini MJ, Fontes CJ, Kono A, Duarte AJS, Benard G 2008. Altered expression of the costimulatory molecules CD80, CD86, CD152, PD-1 and ICOS on T-cells from paracoccidioidomycosis patients: lack of correlation with T-cell hyporesponsiveness. Clin Immunol 129: 341-349.

Castaño D, Barrera LF, Rojas M 2011. Mycobacterium tuberculosis alters the differentiation of monocytes into macrophages in vitro. Cell Immunol 268: 60-67.

Cederbom L, Hall H, Ivars F 2000. CD4 $4^{+} \mathrm{CD} 25^{+}$regulatory T-cells down-regulate co-stimulatory molecules on antigen-presenting cells. Eur J Immunol 30: 1538-1543.

Collins AV, Brodie DW, Gilbert RJ, Iaboni A, Manso-Sancho R, Walse B, Stuart DI, van der Merwe PA, Davis SJ 2002. The interaction properties of costimulatory molecules revisited. Immunity 17: 201-210.

Creery WD, Diaz-Mitoma F, Filion L, Kumar A 1996. Differential modulation of B7-1 and B7-2 isoform expression on human monocytes by cytokines which influence the development of $\mathrm{T}$ helper cell phenotype. Eur J Immunol 26: 1273-1277.

Fife BT, Bluestone JA 2008. Control of peripheral T-cell tolerance and autoimmunity via the CTLA-4 and PD-1 pathways. Immunol Rev 224: 166-182.

Fife BT, Guleria I, Gubbels Bupp M, Eagar TN, Tang Q, Bour-Jordan H, Yagita H, Azuma M, Sayegh MH, Bluestone JA 2006. Insulininduced remission in new-onset NOD mice is maintained by the PD-1-PD-L1 pathway. J Exp Med 203: 2737-2747.

Fife BT, Pauken KE, Eagar TN, Obu T, Wu J, Tang Q, Azuma M, Krummel MF, Bluestone JA 2009. Interactions between PD-1 and PD-L1 promote tolerance by blocking the TCR-induced stop signal. Nat Immunol 10: 1185-1192. 
Filion LG, Matusevicius D, Graziani-Bowering GM, Kumar A, Freedman MS 2003. Monocyte-derived IL-12, CD86 (B7-2) and CD40L expression in relapsing and progressive multiple sclerosis. Clin Immunol 106: 127-138.

Girndt M, Sester M, Sester U, Kaul H, Köhler H 2001. Defective expression of B7-2 (CD86) on monocytes of dialysis patients correlates to the uremia-associated immune defect. Kidney Int 59: 1382-1389.

Greenwald RJ, Freeman GJ, Sharpe AH 2005. The B7 family revisited. Anпu Rev Immunol 23: 515-548.

Lanzavecchia A, Sallusto F 2000. From synapses to immunological memory: the role of sustained T cell stimulation. Curr Opin Immunol 12: 92-98.

Lenschow DJ, Walunas TL, Bluestone JA 1996. CD28/B7 system of T cell costimulation. Annu Rev Immunol 14: 233-258.

Moubasher AD, Kamel NA, Zedan H, Raheem DD 1998. Cytokines in leprosy. I. Serum cytokine profile in leprosy. Int J Dermatol 37: $733-740$

Mueller DL, Jenkins MK, Schwartz RH 1989. Clonal expansion versus functional clonal inactivation: a costimulatory signalling pathway determines the outcome of $\mathrm{T}$ cell antigen receptor occupancy. Annu Rev Immunol 7: 445-480.

Murray RA, Siddiqui MR, Mendillo M, Krahenbuhl J, Kaplan G 2007. Mycobacterium leprae inhibits dendritic cell activation and maturation. J Immunol 178: 338-344.
Palermo ML, Pagliari C, Trindade MAB, Yamashitafuji TM, Duarte AJS, Cacere CR, Benard G 2012. Increased expression of regulatory $\mathrm{T}$ cells and down regulatory molecules in lepromatous leprosy. Am J Trop Med Hyg 86: 878-883.

Santos DO, Castro HC, Bourguignon SC, Bastos OM, Rodrigues CR, Van Heuverswyn H, Nery JA, Miranda A 2007. Expression of B7-1 costimulatory molecules in patients with multibacillary leprosy and reactional states. Clin Exp Dermatol 32: 75-80.

Schlienger K, Uyemura K, Jullien D, Sieling PA, Rea TH, Linsley PS, Modlin RL 1998. B7-1, but not CD28, is crucial for the maintenance of the $\mathrm{CD}^{+} \mathrm{T}$-cell responses in human leprosy. J Immunol 161: $2407-2413$.

Schneider H, Downey J, Smith A, Zinselmeyer BH, Rush C, Brewer JM, Wei B, Hogg N, Garside P, Rudd CE 2006. Reversal of the TCR stop signal by CTLA-4. Science 313: 1972-1975.

Sinsimer D, Fallows D, Peixoto B, Krahenbuhl J, Kaplan G, Manca C 2010. Mycobacterium leprae actively modulates the cytokine response in naïve human monocytes. Infect Immun 78: 293-300.

WHO - World Health Organization 2010. Leprosy - global situation 2010. Wkly Epidemiol Rec 85: 337-348.

Yamamura M, Uyemura K, Deans RJ, Weinberg K, Rea TH, Bloom BR, Modlin RL 1991. Defining protective responses to pathogens: cytokine profiles in leprosy lesions. Science 254: 277-279.

Zhu Y, Yao S, Chen L 2011. Cell surface signaling molecules in the control of immune responses: a tide model. Immunity 34: 466-478. 